Pacific Journal of Mathematics

ON THE SOLVABILITY OF $x^{e} \equiv e(\bmod p)$ 


\section{ON THE SOLVABILITY OF $x^{e} \equiv e(\bmod p)$}

\section{J. B. Muskat}

1. Let $e$ be an integer greater than 1 . Let $p$ be a prime $\equiv 1$ $(\bmod e)$. What conditions must $p$ satisfy if $e$ is an $e$ th power residue, modulo $p$ ?

Let $g$ be a fixed primitive root, modulo $p$. If $p \nmid a$, define ind $a$ as the least nonnegative integer $t$ such that $g^{t} \equiv a(\bmod p)$. For fixed $h, k, 0 \leqq h, k \leqq e-1$, define the cyclotomic number $(h, k)$ as the number of solutions of

$$
\text { ind } n \equiv h(\bmod e) \text {, ind }(n+1) \equiv k(\bmod e), 1 \leqq n \leqq p-2 \text {. }
$$

Let $f=(p-1) / e$. It is well known that

$$
\begin{array}{rlrl}
(h, k) & =(e-h, k-h), & \\
(h, k) & =(k, h), & & f \text { even, } \\
(h, k) & =(k+e / 2, h+e / 2), & f \text { odd }, & \\
\sum_{h=0}^{e-1}(h, k) & = \begin{cases}f-1, & k=0, \\
f, & 1 \leqq k \leqq e-1,\end{cases} \\
\sum_{k=0}^{e-1}(h, k) & = \begin{cases}f-1, & f \text { even, } h=0, \\
f-1, & f \text { odd, } h=e / 2, \\
f, & \text { otherwise } .\end{cases}
\end{array}
$$

Let $\zeta_{e}$ denote a primitive eth root of unity. Define the primitive $e$ th power character $\chi_{p}(a)=\zeta_{e}^{\text {ind } a}$ for $a \neq 0(\bmod p)$.

TheOREM 1. ind $e \equiv(p-1) / 2-\sum_{h=1}^{e-1}(h, 0) h(\bmod e)$.

Proof. Let $z \equiv g^{\rho}(\bmod p)$. Then

$$
e \equiv \prod_{k=1}^{e-1}\left(1-z^{k}\right)(\bmod p) .
$$

For a fixed $v, 0 \leqq v \leqq e-1$, let $\sum_{v}$ and $\Pi_{v}$ denote the sum and the product, respectively, over all $n, 1 \leqq n \leqq p-1$, such that ind $n \equiv v(\bmod e)$. Define

$$
\sum_{v}^{\prime}=\sum_{v}, v \neq 0 ; \sum_{0}^{\prime}=\sum_{n \neq 1}
$$

Then

Received April 17, 1963. This research was supported in part by the National Science Foundation, Research Grant No. G 11309. Reproduction in whole or in part is permitted for any purpose of the United States Government. 


$$
x^{\gamma}-z^{v} \equiv \Pi_{v}(x-n)(\bmod p) \text {. }
$$

Set $x=1$. Then

$$
1-z^{v} \equiv \Pi_{v}(1-n)(\bmod p)
$$

Thus

$$
\text { ind } \begin{aligned}
e & \equiv \sum_{v=1}^{e-1} \sum_{v} \text { ind }(1-n) \\
& \equiv \sum_{v=0}^{e-1} \sum_{v}^{\prime} \text { ind }(1-n)-\sum_{0}^{\prime} \text { ind }(1-n) \\
& \equiv \sum_{u=1}^{p-1} \text { ind } u-\text { ind } 1-\sum_{0}^{\prime}[\text { ind }(-1)+\text { ind }(n-1)] \\
& \equiv f e(e-1) / 2-(f-1) e f / 2-\sum_{0}^{\prime} \text { ind }(n-1) \\
& \equiv e f / 2-\sum_{h=1}^{e-1}(h, 0) h(\bmod e) .
\end{aligned}
$$

$(\bmod e)$.

CoROLlaRY 1. If $e$ is odd, ind $e \equiv \sum_{h=1}^{(e-1) / 2} h[(e-h, 0)-(h, 0)]$

2. Hereafter, let $e$ be an odd prime.

Define the Jacobi sum

$\pi(j, k)=\sum_{n=2}^{p-1} \chi_{p}^{j}(n) \chi_{p}^{k}(1-n)=\sum_{n=1}^{p-2} \chi_{p}^{k}(n) \chi_{p}^{j}(n+1), j, k, j+k \neq 0(\bmod e)$.

It can be shown easily that

$$
\pi(v k, k)=\sum_{i=0}^{e-1} B(i, v) \zeta_{e}^{k i}
$$

where

$$
B(i, v)=\sum_{h=0}^{e-1}(h, i-v h) .
$$

Also, if $v^{\prime}$ is any solution of $v v^{\prime} \equiv 1(\bmod e)$,

$$
B(i, v)=B(i, e-v-1)=B\left(i v^{\prime}, v^{\prime}\right)
$$

It will be demonstrated that for $e$ an odd prime, ind $e(\bmod e)$ can be expressed as a linear combination of $B(i, v)$, the rational integral coefficients of Jacobi sums. N. C. Ankeny gave a similar criterion, expressed in terms of the coefficients of the eth power Gaussian sum

$$
\tau\left(\chi_{p}\right)^{e}=p \prod_{k=1}^{e-2} \pi(1, k),
$$

and a variation of this criterion was found by the author [2, pp. 103, 108]. 
Set

$$
S=\sum_{i=1}^{(e-1) / 2} i \sum_{v=1}^{e-2}[B(e-i, v)-B(i, v)]
$$

TheOREM 2. If $e$ is an odd prime, then $e$ ind $e \equiv S\left(\bmod e^{2}\right)$.

Proof. If

$$
\begin{aligned}
1 \leqq & \leqq e-1, \sum_{v=1}^{e-2} B(i, v)=\sum_{v=1}^{e-2} \sum_{h=0}^{e-1}(h, i-v h) \\
& =\sum_{v=1}^{e-2}(0, i)+\sum_{h=1}^{e-1} \sum_{v=1}^{e-2}(h, i-v h) \\
& =(e-2)(0, i)+\sum_{h=1}^{e-1}\left[-(h, i)-(h, i+h)+\sum_{v=0}^{e-1}(h, i-v h)\right] \\
& =(e-2)(0, i)+\sum_{h=1}^{e-1}[-(h, i)-(e-h, i)+f], \text { by (1) and (4), } \\
& =(e-2)(0, i)-2[f-(0, i)]+(e-1) f, \text { by }(3), \\
& =(i, 0) e+(e-3) f, \text { by }(2) .
\end{aligned}
$$

Thus,

$$
e[(e-i, 0)-(i, 0)]=\sum_{v=1}^{e-2}[B(e-i, v)-B(i, v)] .
$$

Substituting (6) into Corollary 1 yields the theorem.

Corollary 2. If $e$ is an odd prime, $e$ is an eth power residue, modulo $p$, if and only if $S \equiv 0\left(\bmod e^{2}\right)$.

C. E. Bickmore presented without proof criteria (attributed to L. Tanner) for $e=5$ and $e=7[1, \mathrm{pp} .29,36]$. These criteria, (7) and (8), follow from Theorem 2:

Hereafter, let $B(i, 1)=d_{i}, B(i, 2)=c_{i}$.

If $e=5, B(i, 3)=B(i, 1), B(i, 2)=B(3 i, 3)=B(3 i, 1)$, by (5).

$$
\begin{aligned}
5 \text { ind } 5 & \equiv\left[2\left(d_{4}-d_{1}\right)+\left(d_{2}-d_{3}\right)\right]+2\left[2\left(d_{3}-d_{2}\right)+\left(d_{4}-d_{1}\right)\right] \\
& \equiv 4\left(d_{4}-d_{1}\right)+3\left(d_{3}-d_{2}\right)(\bmod 25) .
\end{aligned}
$$

Multiply the congruence by 6 :

$$
5 \text { ind } 5 \equiv d_{1}-d_{4}+7\left(d_{2}-d_{3}\right)(\bmod 25) \text {. }
$$

(Theorem 1 is a generalization of a proof of (7) which Emma Lehmer communicated to the author.)

If $e=7, B(i, 5)=B(i, 1), B(i, 3)=B(5 i, 5)=B(5 i, 1), B(i, 4)=B(i, 2)$, by (5). Also, $B(1,2)=B(2,2)=B(4,2), B(3,2)=B(5,2)=B(6,2)$, by 
(1) and (2).

$$
\begin{aligned}
7 \text { ind } 7 & \equiv\left[2\left(d_{6}-d_{1}\right)+2\left(c_{6}-c_{1}\right)+\left(d_{2}-d_{5}\right)\right] \\
& +2\left[2\left(d_{5}-d_{2}\right)+2\left(c_{5}-c_{2}\right)+\left(d_{4}-d_{3}\right)\right] \\
& +3\left[2\left(d_{4}-d_{3}\right)+2\left(c_{4}-c_{3}\right)+\left(d_{6}-d_{1}\right)\right] \\
& \equiv 5\left(d_{6}-d_{1}\right)+3\left(d_{5}-d_{2}\right)+8\left(d_{4}-d_{3}\right)(\bmod 49) .
\end{aligned}
$$

Multiply the congruence by 39 :

$$
28 \text { ind } 7 \equiv d_{1}-d_{6}-19\left(d_{2}-d_{5}\right)-18\left(d_{3}-d_{4}\right)(\bmod 49) .
$$

The author is grateful to the referee for his helpful suggestions.

\section{BIBLIOGRAPHY}

1. C. E. Bickmore, On the Numerical Factors of $a^{n}-1$ (Second Notice), The Messenger of Mathematics, 26 (1896), 1-38.

2. J. B. Muskat, On Certain Prime Power Congruences, Abhandlungen aus dem mathematischen Seminar der Universität Hamburg, 26 (1963), 102-110.

3. A. L. Whiteman, The Cyclotomic Numbers of Order Ten, Proceedings of the Symposia in Applied Mathematics, Vol. 10, 95-111, American Mathematical Society, Providence, Rhode Island, 1960.

UNIVERSITY OF PitTSBURgh 


\section{PACIFIC JOURNAL OF MATHEMATICS}

\section{EDITORS}

Robert Osserman

Stanford University

Stanford, California

M. G. Arsove

University of Washington

Seattle 5 , Washington
J. DugundjI

University of Southern Califorma: Los Angeles 7, California

Lowell J. Paige

University of California

Los Angeles 24, California

\section{ASSOCIATE EDITORS}

E. F. BECKENBACH

B. H. NeumanN

F. WOLF

K. YosIDA

\section{SUPPORTING INSTITUTIONS}

UNIVERSITY OF BRITISH COLUMBIA

CALIFORNIA INSTITUTE OF TECHNOLOGY

UNIVERSITY OF CALIFORNIA

MONTANA STATE UNIVERSITY

UNIVERSITY OF NEVADA

NEW MEXICO STATE UNIVERSITY

OREGON STATE UNIVERSITY

UNIVERSITY OF OREGON

OSAKA UNIVERSITY

UNIVERSITY OF SOUTHERN CALIFORNIA
STANFORD UNIVERSITY

UNIVERSITY OF TOKYO

UNIVERSITY OF UTAH

WASHINGTON STATE UNIVERSITY

UNIVERSITY OF WASHINGTON

AMERICAN MATHEMATICAL SOCIETY CALIFORNIA RESEARCH CORPORATION SPACE TECHNOLOGY LABORATORIES NAVAL ORDNANCE TEST STATION 


\section{Pacific Journal of Mathematics}

\section{Vol. 14, No. 1 \\ May, 1964}

Richard Arens, Normal form for a Pfaffian .........................

Charles Vernon Coffman, Non-linear differential equations on cones in Banach

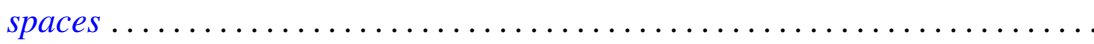

Ralph DeMarr, Order convergence in linear topological spaces ..............

Peter Larkin Duren, On the spectrum of a Toeplitz operator ................

Robert E. Edwards, Endomorphisms of function-spaces which leave stable all

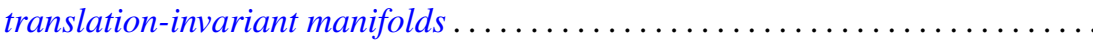

Erik Maurice Ellentuck, Infinite products of isols . . . . . . . . . . . . . . . . 49

William James Firey, Some applications of means of convex bodies . . . . . . . . 53

Haim Gaifman, Concerning measures on Boolean algebras ............. 61

Richard Carl Gilbert, Extremal spectral functions of a symmetric operator. . . . . . 75

Ronald Lewis Graham, On finite sums of reciprocals of distinct nth powers ..... 85

Hwa Suk Hahn, On the relative growth of differences of partition functions ...... 93

Isidore Isaac Hirschman, Jr., Extreme eigen values of Toeplitz forms associated

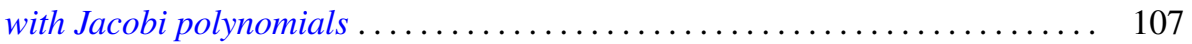

Chen-jung Hsu, Remarks on certain almost product spaces . . . . . . . . . . . 163

George Seth Innis, Jr., Some reproducing kernels for the unit disk . . . . . . . . . 177

Ronald Jacobowitz, Multiplicativity of the local Hilbert symbol . . . . . . . . . . . 187

Paul Joseph Kelly, On some mappings related to graphs ................. 191

William A. Kirk, On curvature of a metric space at a point . . . . . . . . . . . . 195

G. J. Kurowski, On the convergence of semi-discrete analytic functions . . . . . . . 199

Richard George Laatsch, Extensions of subadditive functions . . . . . . . . . . . 209

V. Marić, On some properties of solutions of $\Delta \psi+A\left(r^{2}\right) X \nabla \psi+C\left(r^{2}\right) \psi=0 \ldots 217$

William H. Mills, Polynomials with minimal value sets . . . . . . . . . . . 225

George James Minty, Jr., On the monotonicity of the gradient of a convex

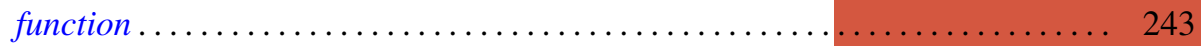

George James Minty, Jr., On the solvability of nonlinear functional equations of 'monotonic' type ................................... 249

J. B. Muskat, On the solvability of $x^{e} \equiv e(\bmod p) \ldots \ldots \ldots \ldots \ldots \ldots \ldots \ldots . \ldots \ldots$

Zeev Nehari, On an inequality of $P . R$. Bessack ................... 261

Raymond Moos Redheffer and Ernst Gabor Straus, Degenerate elliptic

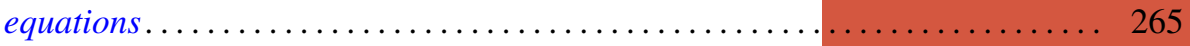

Abraham Robinson, On generalized limits and linear functionals . . . . . . . . . 269

Bernard W. Roos, On a class of singular second order differential equations with a

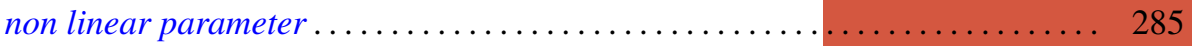

Tôru Saitô, Ordered completely regular semigroups . . . . . . . . . . . . . . . . 295

Edward Silverman, A problem of least area ....................... 309

Robert C. Sine, Spectral decomposition of a class of operators . . . . . . . . . 333

Jonathan Dean Swift, Chains and graphs of Ostrom planes . . . . . . . . . . . 353

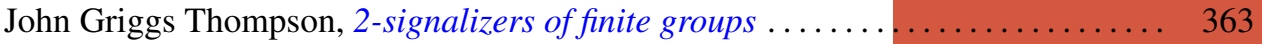

Harold Widom, On the spectrum of a Toeplitz operator . . . . . . . . . . . . . 365 